\title{
Visual Word Recognition in Bilinguals: Phonological Priming From the Second to the First Language
}

\author{
Ilse Van Wijnendaele \\ University of Leuven
}

\author{
Marc Brysbaert \\ Ghent University
}

\begin{abstract}
In this study, the authors show that cross-lingual phonological priming is possible not only from the 1st language (L1) to the 2nd language (L2), but also from L2 to L1. In addition, both priming effects were found to have the same magnitude and to not be related to differences in word naming latencies between L1 and L2. The findings are further evidence against language-selective access models of bilingual word processing and are more in line with strong phonological models of visual word recognition than with the traditional dual-route models.
\end{abstract}

Until 1990, the general idea was that bilinguals had two mental lexicons: one for the first language and one for the second. In addition, a language switch mechanism controlled which lexicon was active. Such an architecture of language selective access seemed ideal to explain why, in general, bilinguals do not experience interference problems from one language to the other. In recent years, however, evidence has accumulated showing that the first stages of visual word recognition are largely language independent and that the assumption of independent lexicons may be incorrect. Subsequently, we give a summary of this evidence (for further discussion, see Brysbaert, 1998; Brysbaert, Van Dyck, \& Van de Poel, 1999; Dijkstra, Timmermans, \& Schriefers, 2000; van Heuven, Dijkstra, \& Grainger, 1998).

First, in lexical decision tasks, it has been shown that bilingual participants cannot suppress one of their languages, even when the task strongly urges them to do so because of interference costs. For instance, it has been shown repeatedly that if the nonword trials contain words of the nontarget language, there are large processing costs associated with these trials (e.g., Nas, 1983). In addition, these trials have strong inhibitory effects on the processing of interlingual homographs (i.e., words that exist in both languages but have different meanings; De Groot, Delmaar, \& Lupker, 2000; Dijkstra, Grainger, \& van Heuven, 1999; Dijkstra, Van Jaarsveld, $\&$ Ten Brinke, 1998). The magnitude of the inhibitory effect depends on the relative frequency of the homograph in the target and the nontarget language. Recently, Dijkstra et al. (2000) reported that the frequency-dependent interference effect not only

Ilse Van Wijnendaele, Department of Experimental Psychology, University of Leuven, Leuven, Belgium; Marc Brysbaert, Department of Experimental Psychology, Ghent University, Ghent, Belgium.

This research was made possible by Inter University Attraction Poles Grant P4/19 from the Department of Science Policy of the Belgian Federal Government. We thank Wido La Heij, Guy Van Orden, and Laurie Feldman for helpful comments on an earlier draft of the article.

Correspondence concerning this article should be addressed to Ilse Van Wijnendaele, Department of Experimental Psychology, University of Leuven, Tiensestraat 102, B-3000 Leuven, Belgium. E-mail: Ilse. vanwijnendaele@psy.kuleuven.ac.be appears in a lexical decision task (e.g., for a Dutch-English bilingual, Is this a Dutch word or not?), but also in a go/no-go paradigm (e.g., Press on the key when the stimulus is a Dutch word only), despite that in the latter paradigm, there is little discussion that performance would be best if the nontarget language system were simply suppressed.

Second, researchers have extended basic findings of monolingual language processing to bilingual processing. Bijeljac-Babic, Biardeau, and Grainger (1997), for instance, looked at the inhibition effect of orthographic neighbors. Previous research (e.g., Segui \& Grainger, 1990) had shown that low-frequency target words are more difficult to recognize if, immediately before, a high-frequency orthographic neighbor has been presented tachistoscopically than if an orthographically dissimilar control word has been presented (i.e., recognition of the word BLUR is hampered when it is preceded by the masked prime blue). Such an effect was predicted on the basis of the interactive activation model (McClelland \& Rumelhart, 1981), which sees word identification as the result of competition between orthographically similar words. Bijeljac-Babic et al. (1997) showed that the inhibition effect is present not only for intralingual neighbors, but also for crosslingual neighbors. Thus, highly proficient French-English bilinguals experienced more problems processing the French word $A M O N T$ when it was preceded by the masked English prime among than when it was preceded by the control word drive. No effect was found for monolinguals and beginning bilinguals, as expected, because the inhibition effect depends on word frequency.

Brysbaert et al. (1999) started from the claim recently made that recognition of visually presented words involves automatic, prelexical phonological coding (e.g., Frost, 1998; Perfetti \& Bell, 1991; Van Orden, 1987). They reasoned that if letters must be converted to sounds before printed words can be recognized, and if the conversion cannot be strategically controlled, then the coding should occur for all grapheme-phoneme correspondences mastered by an individual. To examine this issue, Brysbaert et al. used the masked homophonic priming effect first described by Humphreys, Evett, and Taylor (1982) for word primes, and later extended by Perfetti and Bell (1991) to nonword primes. Humphreys 
et al. showed that a tachistoscopically presented English target has more chances of being recognized when it is preceded by a masked English homophonic prime (e.g., male-MAIL) than when it is preceded by a graphemic control prime that shares the same number of letters with the target word but not the same number of sounds (mall-MAIL). Perfetti and Bell reported that the effect can be replicated with pseudohomophonic nonword primes (e.g., creap-CREEP vs. crelp-CREEP), provided that the presentation time of the prime is longer than $35 \mathrm{~ms}$.

Brysbaert et al. (1999) investigated two issues. First, they explored whether it was possible to obtain a pseudohomophonic priming effect when the target language was not the participants' first language (L1) but their second (L2). To answer this question, they presented French stimuli to French monolinguals and to Dutch-French bilinguals. The French stimuli were borrowed from Ferrand and Grainger (1993, 1994; Grainger \& Ferrand, 1996), who replicated Perfetti and Bell's (1991) pseudohomophone effect in French and also showed that in addition to the phonological overlap between prime and target, the orthographic overlap between both stimuli plays a role as well. The stimuli Ferrand and Grainger used not only contained the usual pseudohomophonic trials ( fain-FAIM) and graphemic control trials (faic-FAIM), but also included a second type of pseudohomophonic trials that had but a very small orthographic overlap with the target word (fintFAIM). This last type of trial is possible in French, because it has fairly unrestricted phoneme-grapheme correspondences with transparent grapheme-phoneme correspondences, so that the same sounds can be represented by quite different sequences of letters that have the same pronunciation. Using this type of stimuli, Ferrand and Grainger showed effects of both orthography and phonology in visual word recognition. The effect of orthographic similarity was demonstrated by comparing target word processing after the homophonic primes fain and fint; the effect of phonological similarity was demonstrated by comparing performance after the homophonic prime fain and the nonhomophonic prime faic. Brysbaert et al. (1999) first replicated Grainger and Ferrand (1996) with French monolinguals and then showed nearly the same effects with Dutch-French bilinguals (see the first three columns of Table 1 , which appears later in this article, for the exact data). Brysbaert et al. interpreted this pattern of results as evidence for the idea that the same processes underlie visual word recognition in L1 and in L2.

The second issue Brysbaert et al. (1999) investigated was whether one could obtain not only an intralingual homophonic effect (either in L1 or in L2), but also a cross-lingual homophonic effect from L1 on L2. To address this question, they constructed a new type of stimuli, in which the homophonic primes were not homophonic according to the letter-sound correspondences of L2 (the target language), but were homophonic according to the letter-sound correspondences of L1. Examples of such stimuli for Dutch-English bilinguals are the prime-target couples mee-MAY and bleem-BLAME. Mee (with, along) is a Dutch word with the same pronunciation as the English word may; bleem is not a word in Dutch or English, but in Dutch is pronounced the same as the English word blame.

In their first experiment, Brysbaert et al. (1999) presented Dutch-French counterparts of the mee-MAY examples to DutchFrench bilinguals, to determine whether a word in L1 would prime a homophone in L2. Therefore, they compared target word recog- nition for homophonic stimulus pairs such as wie-OUI with target word recognition for graphemic control pairs such as jij-OUI (wie [who] and jij [you] are Dutch words of matched frequencies; the former is pronounced like the French word oui [yes]). Brysbaert et al. indeed found that recognition of the target word OUI was better after the tachistoscopically presented cross-lingual homophonic prime wie (30\%) than after the graphemic control prime jij (23\%). In their second experiment, they replicated the homophonic effect with pseudohomophones (i.e., primes of the type bleem-BLAME). Thus, the French target word SOURD (deaf) was more likely to be recognized after the cross-lingual pseudohomophone soer $(41 \%)$ than after the graphemic control nonword siard (34\%; see the second row of Table 2, which appears later in the article). No cross-lingual homophone effect was obtained for French monolinguals. For these participants, the target word OUI did not have more chances of being recognized after the prime wie $(35 \%)$ than after the prime jij (36\%). Similarly, the target word SOURD was not more likely to be recognized after soer (24\%) than after siard (33\%; in fact, the reverse effect was observed, probably because in French, the nonword siard resembles the word sourd more than soer; see the first row of Table 2, below). An interaction between bilingualism and the phonological priming effect is pivotal, because otherwise the effect cannot be ascribed unequivocally to the simultaneous mastery of two different languages (see Brysbaert et al., 1999, for further details).

Brysbaert et al. (1999) interpreted their findings as compatible with a strong phonological model of visual word recognition: Even though participants were trying to identify target words in L2, they could not prevent themselves from being influenced by the phonological overlap between target and prime on the basis of the L1 spelling-sound correspondences (i.e., the cross-lingual homophonic priming effect). At the same time (because both types of stimuli were mixed), participants were also influenced by the L2 grapheme-phoneme correspondences (as evidenced by the intralingual homophonic priming effect). This pattern of results agrees with a mandatory, prelexical, language-independent activation of phonological codes on the basis of orthographic stimuli.

However, it might be argued that Brysbaert et al.'s (1999) findings are not really strong evidence against the traditional dual-route models of visual word recognition (Coltheart, 1978; Coltheart, Curtis, Atkins, \& Haller, 1993; Coltheart, Rastle, Perry, Langdon, \& Ziegler, 2001). ${ }^{1}$ In these models, visual word recognition involves the combined activity of an orthographic lexicon (the lexical route) and a rule-based grapheme-phoneme conversion (GPC) system (the nonlexical route). The simplest extension to the bilingual situation would probably involve a bilingual lexicon (e.g., similar to the one implemented by Dijkstra \& van Heuven, 1998) and an augmented GPC system. Certainly in the case of sequential bilingualism (when L1 is mastered well before L2), the latter would include all GPC rules from the native language, possibly augmented with noncontradicting rules from the second language. These are rules that concern graphemes that are present in L2 but not in L1. Although the different versions of the dual-route model have not yet addressed the simulation of the

\footnotetext{
${ }^{1}$ We discuss dual-route models because there are different versions of the general architecture, depending on how the grapheme-phoneme conversion route has been implemented.
} 
masked phonological priming effect, it could be conceived that such a model might predict a phonological priming effect from L1 on L2. Such a model might also be able to incorporate phonological priming from L2 on L2, as long as the rules involved do not contradict the GPC rules of L1. (Because the GPC system is rule based, deviations from the rules must be handled by the lexical route.) In agreement with this view, the reduced net phonological priming effect in L2 (8\%) compared with L1 (16\%; see the first three rows of Table 1, below) could be interpreted as evidence for the idea that phonological priming in L2 is more limited than phonological priming in L1 and restricted to those instances in which L2 GPCs do not violate L1 GPCs.

A way to more clearly decide between the strong phonological models of bilingual word processing and the dual-route models is to look at whether it is possible to prime L1 target words with L2 pseudohomophones. If the GPC system does not include lettersound correspondences that deviate from the L1 graphemephoneme correspondences, then a dual-route model predicts that phonological priming from L2 to L1 will be very limited. For instance, in English-Dutch bilinguals, the nonword bleem is not expected to prime the target word BLAME, because the grapheme $e e$ already maps to the phoneme /i/ and thus can no longer be linked to the phoneme /e/. In contrast, a strong phonological model of visual word recognition predicts very similar phonological priming from L2 on L1 as from L1 on L2, because phonological coding is mandatory in both languages and all letter-sound correspondences are activated automatically and in parallel.

Thus, the evidence in favor of a strong phonological model of bilingual visual word processing would become more compelling if cross-lingual phonological priming were shown from L2 primes to L1 targets. This is what we investigated in Experiment 2. In Experiment 1, we looked at the naming latencies for words in L1 and L2. There were two reasons for doing so: First, word naming times could provide us with an interesting measure of language proficiency in bilinguals, and second, different theories of visual word recognition make different predictions about the correlation between prelexical phonological coding and word naming times. The importance of these two issues is outlined in the introductions of Experiments 1 and 2, respectively.

\section{Experiment 1}

In the early days of research on bilingualism, researchers were mainly interested in so-called balanced bilinguals. These are persons who master two languages to the same degree and who can use both languages in virtually every situation. Usually, they are individuals who have been raised bilingually from their birth (e.g., because their parents spoke different languages, or because the language of the family differed from the language of the school environment). Subsequent research has indicated, however, that completely balanced bilinguals are very rare, because it is too effortful to consistently use both languages for all conversation topics (e.g., physics vs. cooking) and in all modalities (e.g., listening vs. writing; for a review, see Schaerlaekens, 1998). Furthermore, investigators have realized that research on balanced bilingualism has limited practical value, because the vast majority of people who know more than one language are unbalanced bilinguals, with less than perfect knowledge of their second language.
Research with unbalanced bilinguals, however, raises the problem of determining the proficiency level in both languages, as argued most strongly by Grosjean $(1997,1998)$. In this respect, Grosjean points to the importance of a long series of subjectrelated factors, such as language history, language stability, number and type of languages known, competence within the four skills (reading, writing, speaking, and listening), domain-specific use of the languages, language modes, code switching, and so on. Given this large heterogeneity of bilingual skills, it becomes clear that to decide about the proficiency level of a person, it is necessary to use a task that is strongly related to the area of expertise one is addressing. Thus, because we wanted to assess the proficiency of the participants with respect to phonological coding in visual word recognition, we needed a task that is related to the pronunciation of written words rather than a task that concerns the writing of grammatically correct texts.

There is some evidence that bilinguals are slower to read aloud printed words in their second language than in their first language. For instance, La Heij, Hooglander, Kerling, and van der Velden (1996) reported color-word naming times of $443 \mathrm{~ms}$ in L1 and 456 $\mathrm{ms}$ in L2 (Experiment 1). For the reading of concrete words (Experiment 2), the naming times were respectively $441 \mathrm{~ms}$ and 473 ms. Similarly, Kroll and Stewart (1994, Experiment 3) reported that word naming in L2 took $91 \mathrm{~ms}$ longer than word naming in L1. So, an interesting way to assess the vocabulary proficiency in L1 and L2 may be simply to ask participants to read aloud words in both languages and to measure the voice onset times. Experiment 1 was designed to test the usefulness of such a task, by directly comparing the naming latencies of two complementary groups of bilinguals (French-Dutch vs. Dutch-French) with the same sets of stimuli.

In addition, we manipulated word frequency in both languages, to gather the effect of this variable in second language reading compared with first language reading. Traditionally, the frequency effect in word naming has been considered a marker of lexical involvement in the naming process. It has been shown that the frequency effect is stronger in the naming of words with an opaque correspondence between letters and sounds than in the naming of words with a transparent relation. For instance, Frost, Katz, and Bentin (1987) showed that the frequency effect is stronger in the naming of Hebrew and English words, which have many spellingsound ambiguities, than in the naming of Serbo-Croatian words, which have a much simpler mapping between letters and sounds. In line with the dual-route model, Frost et al. interpreted the larger frequency effect in Hebrew and English as evidence for a greater contribution of the lexical route in the correct naming of visually presented words in these languages. Frost (1998) also interpreted the word frequency effect as evidence for lexical involvement in word naming, but no longer considered it as evidence for a dual-route interpretation. In his new, strong phonological view of visual word recognition, the prelexical phonological code used for lexical access no longer needed to be a fully articulated code, but could be an impoverished code that sufficed to activate the correct lexical representation. This impoverished code was largely frequency independent, and the frequency effect in naming arose because a contribution of the mental lexicon was needed for the correct pronunciation of words with ambiguous letter-sound correspondences. 


\section{Method}

Participants. Participants consisted of two groups of bilinguals: one group of French-Dutch bilinguals and one group of Dutch-French bilinguals. The French-Dutch bilinguals were 39 students from the University of Leuven. Their first language was French, and most of them lived and had attended high school in the French-speaking part of Belgium. At the time of the experiment, they studied at the University of Leuven and followed university courses in Dutch. The majority had already finished a graduate program at a French-speaking university. Only 5 participants had started to learn Dutch before the age of 10. The Dutch-French bilinguals were $20 \mathrm{PhD}$ students from the University of Leuven, mainly from the Department of Psychology. All had Dutch as their first language and had started to learn French at the age of 11. None of them had grown up in a bilingual environment. All participants rated their comprehension of the second language as quite good (7 or more on a 10-point rating scale, ranging from bad to excellent), but most of them were less sure about the quality of their production in the second language.

Stimulus materials. Stimulus materials consisted of 154 French words and 160 Dutch words. The words of both languages were matched on frequency, number of letters, number of phonemes, and number of syllables. Words were divided in four frequency categories. Very-lowfrequency words (LLFR) had a frequency of 1-10 occurrences per million words (based on the CELEX counts for the Dutch words [Baayen, Piepenbrock, \& Van Rijn, 1993] and on the Trésor de la Langue Francaise for the French words [Centre National de la Recherche Scientifique, 1971]); low-frequency words (LFR) had a frequency between 10-100 occurrences per million words; high-frequency words (HFR) had a frequency between 100-1,000 occurrences per million words; and very-high-frequency words (HHFR) had a frequency of more than 10,000 occurrences per million words. For each frequency level, words of three, four, five, and six letters were selected (see Appendix A).

Procedure. Participants were seated individually in a quiet room. The instructions were presented on a computer screen. The participants were told that there would first be a practice session with 20 trials, then a short break followed by a naming task in the first language, and then another short break followed by a naming task in the second language. The words had to be read aloud as quickly and as accurately as possible. Each trial started with a blank screen for $1 \mathrm{~s}$, after which two vertically aligned lines appeared at the center of the screen. The participants were asked to fixate the gap between the lines. After the appearance of the lines $(500 \mathrm{~ms})$, a word was presented horizontally in such a way that the second letter was situated in the gap between the lines. Previous research has indicated that the second letter is the optimal viewing position for naming short Dutch and French words (Brysbaert, 1994; Brysbaert, Vitu, \& Schroyens, 1996). Words were presented in lowercase and remained visible until the participant reacted or after $770 \mathrm{~ms}$ had elapsed. We encouraged participants to respond as quickly as possible, but we also told them that it was acceptable to respond even after the word had disappeared from the screen. Reaction times were measured with a voice key connected to the game port and registered to the nearest millisecond, using software routines published by Bovens and Brysbaert (1990). The correctness of the response was encoded on-line by the experimenter, who used three keys of the computer keyboard (for correct, incorrect, or correct but bad time registration).

\section{Results}

The data of 1 French-Dutch bilingual were lost due to a computer failure. Therefore, the analyses described below are based on 38 French-Dutch and 20 Dutch-French bilinguals. Analyses of variance (ANOVAs) with three variables (language group of the participants, language of the words, and word frequency) revealed a reliable main effect of word frequency, $F_{1}(3,168)=39.53, M S E$ $=238, p<.01$, and $F_{2}(3,306)=19.67, M S E=713, p<.01$, but this effect was embedded in a significant interaction with language of the words, $F_{1}(3,168)=4.46, M S E=198, p<.01$, and $F_{2}(3$, $306)=1.81, M S E=736, p>.10$, and a significant triple interaction between language group, language of the words, and word frequency, $F_{1}(3,144)=14.53, M S E=198, p<.01$, and $F_{2}(3,306)=12.67, M S E=348, p<.01$. Figure 1 illustrates the triple interaction. Planned comparisons showed that there was a significant linear relationship between the four levels of word frequency and the naming latencies for Dutch as a second language, $F_{1}(1,56)=69.84, M S E=253, p<.01$, and $F_{2}(1,306)=$ 42.34, $M S E=436, p<.01$; for French as a second language, $F_{1}(1,56)=50.11, M S E=295, p<.01$, and $F_{2}(1,306)=45.00$, $M S E=624, p<.01$; for French as a first language, $F_{1}(1,56)=$ $10.98, M S E=295, p<.01$, and $F_{2}(1,306)=6.54, M S E=437$, $p<.02$; but not for Dutch as a first language, $F_{1}(1,56)=1.38$, $M S E=253, p>.20$, and $F_{2}(1,306)=1.10, M S E=625, p>.20$. The only other effect that was significant in both the $F_{1}$ and the $F_{2}$ analysis was the interaction between language group of the participants and language of the words, $F_{1}(1,56)=87.48, M S E=$ $2,369, p<.01$, and $F_{2}(1,306)=881.00, M S E=348, p<.01$. The French-Dutch bilinguals were faster to pronounce the French words than the Dutch words (444 ms vs. $482 \mathrm{~ms}$ ), whereas the reverse was true for the Dutch-French bilinguals (485 ms vs. 435 $\mathrm{ms})$.

\section{Discussion}

The results of Experiment 1 confirm that participants are faster to name words in their native language than to name words in their second language. Overall, there was a 40- to 50-ms difference between L1 and L2. The L1 advantage was modulated by word frequency. It was larger for low-frequency words than for highfrequency words, because the frequency effect was more pronounced in L2 than in L1. In fact, the frequency effect in L1 was quite small both for Dutch and French (around $10 \mathrm{~ms}$ ). This is in agreement with figures previously published for these languages (e.g., Brysbaert, Lange, \& Van Wijnendaele, 2000; Peereman \&

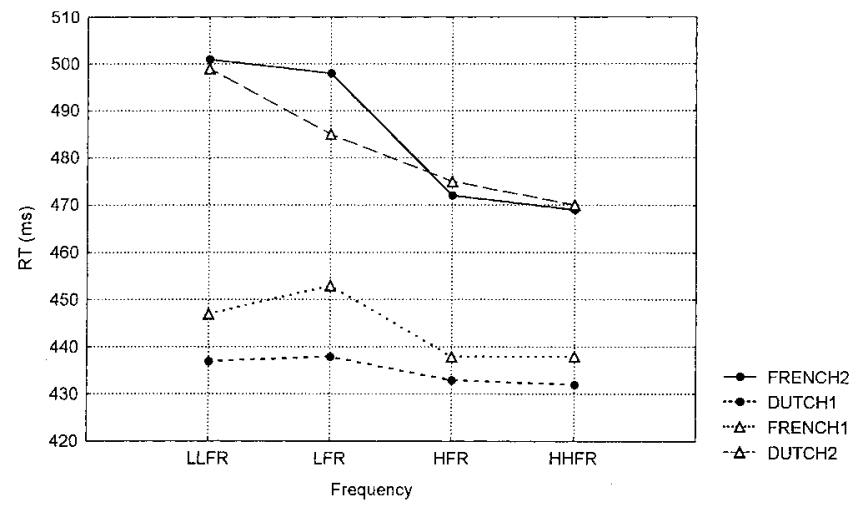

Figure 1. Word naming latencies as a function of native language of the participants, language of the stimuli, and word frequency (Experiment 1). The French-Dutch bilinguals were the participants of Experiment 2; the Dutch-French bilinguals were a different group. RT $=$ response times; $1=$ first language; 2 = second language; $L L F R=$ very-low-frequency words; LFR $=$ low-frequency words; HFR $=$ high-frequency words; HHFR = very-high-frequency words. 
Content, 1995) and is probably related to both languages generally having a transparent mapping between graphemes and phonemes (Van den Bosch, Content, Daelemans, \& De Gelder, 1994). In contrast, second-language word naming is more frequency sensitive.

As indicated in the introduction, the word frequency effect is often interpreted as a marker for lexical involvement in word naming, both within the dual-route models of word naming (Coltheart et al., 1993, 2001; Frost et al., 1987) and within some strong phonological models of visual word recognition (Frost, 1998). Therefore, the absence of a strong frequency effect in L1 reading suggests that word naming in Dutch and French is largely mediated by nonlexical spelling-sound conversions. The clear frequency effect for the same words when they are not part of the native language indicates that correct word naming in L2 requires more lexical mediation than word naming in L1.

The results of Experiment 1 also confirm that the word naming task can be used to assess language proficiency in bilinguals. In fact, we obtained a nearly symmetric pattern of naming latencies as a function of the language presented (Dutch-French) and the mother tongue of the participants (see Figure 1). This is strong evidence that the differences in naming latencies between L1 and L2 are indeed due to the language proficiency of the participants and are not due to the stimuli used in the different languages (which could have been the case if we had looked at the results of only the French-Dutch bilinguals).

\section{Experiment 2}

Thus far, we have shown that (a) target words from L2 can be primed by homophones from L1 (Brysbaert et al., 1999) and (b) L2 word naming needs more lexical mediation than L1 naming (Experiment 1). These findings can be accounted for by a strong phonological model of bilingual visual word recognition. According to this view, in the first stages of word processing, all spellingsound correspondences mastered by a bilingual are automatically activated and used to select the appropriate lexical representation. This explains why intralingual priming from L2 on L2 as well as cross-lingual priming from L1 on L2 are observed within the same experimental session. To account for the larger frequency effect in L2 word naming than in L1 word naming, one has to assume, similar to Frost (1998), that lexical representations are needed for the fully articulated, correct pronunciation of words with ambiguous spellings.

However, the findings are also in line with a more moderate dual-route model that assumes a bilingual lexicon and a GPC route that is largely restricted to the GPC rules of L1 (see above). According to this model, only regular L1 words can be named nonlexically (giving rise to the small frequency effects in L1 naming for Dutch and French). L2 words require lexical mediation to be named correctly, unless the word consists of graphemes that do not have a different pronunciation in L1, hence the strong frequency effect in L2 word naming.

Although both models can account for the existing data, they make two diverging predictions, which can be used to decide between the models. The first distinguishing prediction is that if the GPC system of the dual-route model is predominantly made up of L1 correspondences, then the dual-route model predicts that it will be very difficult to obtain phonological priming from L2 stimuli on L1 target words. More specifically, whereas a phonological priming effect of the nonword bleem on the target word $B L A M E$ is predicted for Dutch-English bilinguals (in whom the GPC route translates the letters bleem into the sounds /blem/), the same effect is not predicted for English-Dutch bilinguals, because for them the GPC route translates the stimulus bleem into the sounds / blim/, which do not correspond with the phonological representation of the word BLAME. In contrast, a strong phonological model assumes that the stimulus bleem is translated simultaneously into the representations /blem/ and /blim/, both for Dutch-English bilinguals and English-Dutch bilinguals, because the phonological coding occurs prelexically and is not influenced by the language of the prime (the same phenomenon is assumed to happen in English, explaining why words with irregular or inconsistent spelling-sound correspondences can be primed phonologically). Consequently, the strong phonological model does not predict a big difference in phonological priming as a function of whether the prime is part of $\mathrm{L} 1$.

The second prediction that can be used to distinguish between a dual-route model of bilingual word recognition and a strong phonological model is the relationship between the L2 naming latency cost and the amount of cross-lingual phonological priming that can be observed from L2 on L1. According to dual-route models, longer naming latencies in L2 than in L1 are an indication of less nonlexical involvement in the naming of L2 words. As a consequence, these models predict a negative correlation between the time cost of L2 naming and the net cross-lingual phonological priming effect that can be observed in bilingual people (i.e., the larger the L2 naming cost, the less powerful the nonlexical route for L2 and, hence, the smaller the nonlexical phonological priming from L2 to L1). In contrast, strong phonological models need not predict a correlation between the phonological priming effect and the difference in naming latencies, because the phonological priming effect depends on the prelexical conversion of letters into sounds, whereas naming latencies reflect the selection of the correct and fully articulated phonemic representation among those that have been activated (see the Discussion and General Discussion sections below for more details).

To examine these two predictions, we repeated Experiment 2 of Brysbaert et al. (1999) with French-Dutch bilinguals. In their experiment, Brysbaert et al. showed that Dutch-French bilinguals were influenced by the phonological overlap among prime and target according to the letter-sound correspondences of L2 (as evidenced by the superior performance on the homophonic trials fain-FAIM compared with the graphemic control trials faic$F A I M)$ and by the phonological overlap according to the lettersound correspondences of L1 (as evidenced by the superior performance on the trials soer-SOURD compared with the trials siard-SOURD). By reversing the language dominance of the participants, we could investigate what happens when the experiment simultaneously involves the phonological priming from L1 to L1 and from L2 to L1.

To really understand the research issue of the present experiment, it may be best to imagine how the experiment appeared for the participants. For them, the task was simply to identify a series of tachistoscopically presented words in their native language. They were native French speakers and they were asked to identify a few French words. Nothing was said about the existence of primes or that some of the primes sounded like French words if 
they were pronounced according to the Dutch letter-sound correspondences. In fact, no participant even mentioned having seen any of the primes. As far as they were concerned, they were helping us to get some insight into the recognition of shortly presented French words. Dutch was never under discussion. Nevertheless, as described subsequently, their recognition of French words was influenced by the Dutch primes in a way that was not observed in French monolinguals.

\section{Method}

Participants. The participants were the French-Dutch bilinguals from Experiment 1. The present experiment had been finished before the naming task described above, so that the results were not influenced by the naming task. This allowed us to directly compare the findings with those of Brysbaert et al. (1999, Experiment 2).

Stimulus materials. For the French-French stimuli, we used the stimuli listed in Grainger and Ferrand (1996, Appendix; see Appendix B, this article). These stimuli consisted of 30 four-letter words with three types of nonword primes. The first type were pseudohomophones created by changing one letter of the target word (usually the last; e.g., fain-FAIM). The second type of nonwords were the graphemic controls of the first type; these nonwords shared the same letters with the target word, but the letter that had been changed did not preserve the phonemic representation of the target word (e.g., faic-FAIM). Finally, the third type of nonwords included pseudohomophones that had only one letter in the same position as the target words (e.g., fint-FAIM). The phonological priming effect was measured by comparing the effects of prime types 1 and 2, which have the same number of letters in common with the target but not the same number of sounds; the orthographic priming effect was estimated by comparing prime types 1 and 3, which are both pseudohomophones but have a different orthographic overlap with the target word. The average printed frequency of the target words was 260 occurrences per million words (Grainger \& Ferrand, 1996, p. 627).

The Dutch-French stimuli consisted of 36 target words with three types of primes, collected by Brysbaert et al. (1999, Appendix; see Appendix C, this article). French words were selected that had a pronunciation that could be mimicked by a Dutch nonword, according to the Dutch spelling-tosound correspondences (e.g., soer-SOURD). Then, for each word, a graphemic and an unrelated prime were assembled. The graphemic primes were nonwords with the same orthographic overlap with the target (siardSOURD). The unrelated primes had no overlap with the target (chaneSOURD), and thus differed both on the number of shared letters and sounds from the homophonic and the graphemic primes. This type of control prime was included to check whether the priming procedure worked, in case there was no difference between the homophonic and the graphemic control condition. For all primes, Brysbaert et al. tried to avoid letter sequences that were unacceptable in either Dutch or French. Furthermore, they had two native French speakers check all the stimuli to ensure that no prime formed a French word, and that no prime sounded like a French target word when pronounced according to the French grapheme-phoneme correspondences. The average frequency of the French target words was 440 occurrences per million words (Centre National de la Recherche Scientifique, 1971).

Procedure. Participants were seen individually in a quiet room. First, the instructions (in French) were presented on a computer screen. These mentioned that 12 practice trials and 66 test trials would be presented. At the beginning of a trial, two vertical lines appeared at the center of the screen, together with the message that the participant had to press on the space bar to start the trial. A forward mask consisting of six pound symbols (\#\#\#\#\#\#) was presented $500 \mathrm{~ms}$ later, with the second hash mark in the gap between the vertical lines. The forward mask remained on the screen for $500 \mathrm{~ms}$, and was followed by a prime for $42 \mathrm{~ms}$, a target word for $28 \mathrm{~ms}$, and a backward mask (consisting of six pound symbols) that remained on the screen until the end of the trial. All stimuli were left aligned (i.e., the second letter always appeared between the lines). The prime appeared in lowercase letters, and the target appeared in uppercase letters. The participants were told that on each trial, a French word in uppercase letters would be presented, and they should try to identify the word and type it in. They were also told that low scores were normal. The presence of nonword primes was not mentioned. Each participant received a random permutation of the 30 French-French and the 36 Dutch-French stimuli, which were mixed. Participants saw the target words only once, with a different type of prime according to a Latin square design.

\section{Results}

The results are discussed separately for the French-French and the Dutch-French stimuli.

French-French stimuli. Percentages of correct target word identification as a function of prime type are shown in Table 1, last column, next to those of Grainger and Ferrand (1996) and Brysbaert et al. (1999). ANOVAs with the variables of prime type and Latin square group revealed a significant main effect of prime type, $F_{1}(2,72)=33.66, M S E=0.02, p<.01$, and $F_{2}(2,54)=$ $10.10, M S E=0.04, p<.01$. Duncan's multiple range test showed that the net orthographic priming effect of $23 \%$ was significant both across participants and stimulus materials $\left(p_{1}<.01\right.$ and $p_{2}<$ $.01)$; the net phonological priming effect of $7 \%$ was less reliable $\left(p_{1}<.03\right.$ and $\left.p_{2}=.22\right)$.

To further test the relationship of the present data with those obtained by Brysbaert et al. (1999, Experiment 2), we performed an ANOVA on the net phonological priming effect in the three groups of participants (monolingual, Dutch-French bilingual, and French-Dutch bilingual). In this analysis, there was no reliable difference between the groups, $F_{1}(2,96)=2.20, M S E=0.04, p<$ .12 , and $F_{2}(2,58)=2.59, M S E=0.03, p<.09$, although there was trend toward a larger phonological priming effect for the monolingual group (16\%) than for the two bilingual groups $(8 \%$ and $7 \%$ ). The same analysis on the net orthographic priming effect revealed no difference between the three groups, $F_{1}(2,96)<1$, $M S E=0.05$, and $F_{2}(2,58)<1, M S E=0.04$.

Dutch-French stimuli. The percentages of correct target identification of the Dutch-French stimuli as a function of prime type are shown in the last column of Table 2, next to those of Brysbaert et al. (1999, Experiment 2). ANOVAs with the variables of prime type and Latin square group showed a significant effect of prime

Table 1

Percentage Correct Target Identification as a Function of Language Group and Stimulus Type: French-French Stimuli

\begin{tabular}{ccccc}
\hline $\begin{array}{c}\text { Stimulus } \\
\text { type }\end{array}$ & $\begin{array}{c}\text { Monolingual } \\
\text { French }^{\mathrm{a}}\end{array}$ & $\begin{array}{c}\text { Monolingual } \\
\text { French }^{\mathrm{b}}\end{array}$ & $\begin{array}{c}\text { Dutch-French } \\
\text { bilingual }^{\mathrm{b}}\end{array}$ & $\begin{array}{c}\text { French-Dutch } \\
\text { bilingual }^{\mathrm{c}}\end{array}$ \\
\hline fain-FAIM & 72 & 44 & 53 & 55 \\
faic-FAIM & 55 & 28 & 45 & 48 \\
fint-FAIM & 50 & 16 & 25 & 32 \\
$\begin{array}{c}\text { Phonological } \\
\text { priming }\end{array}$ & 17 & 16 & 8 & 7 \\
$\begin{array}{c}\text { Orthographic } \\
\text { priming }\end{array}$ & 22 & 28 & 28 & 23 \\
\hline
\end{tabular}

${ }^{\mathrm{a}}$ Grainger and Ferrand (1996). $\quad{ }^{\mathrm{b}}$ Brysbaert et al. (1999). $\quad{ }^{\mathrm{c}}$ Experiment 2 , this study. 
Table 2

Percentage Correct Target Identification as a Function of Language Group and Stimulus Type: Dutch-French Stimuli

\begin{tabular}{lccc}
\hline \multicolumn{1}{c}{ Stimulus type } & $\begin{array}{c}\text { Monolingual } \\
\text { French }^{\mathrm{a}}\end{array}$ & $\begin{array}{c}\text { Dutch-French } \\
\text { bilingual }^{\mathrm{a}}\end{array}$ & $\begin{array}{c}\text { French-Dutch }_{\text {bilingual }^{\mathrm{b}}} \\
\text { soer-SOURD }\end{array}$ \\
siard-SOURD & 33 & 41 & 48 \\
chane-SOURD & 9 & 34 & 42 \\
Phonological priming & -9 & 16 & 20 \\
\hline
\end{tabular}

${ }^{a}$ Brysbaert et al. (1999). ${ }^{\mathrm{b}}$ Experiment 2, this study.

type, $F_{1}(2,72)=58.44, M S E=0.01, p<.01$, and $F_{2}(2,66)=$ $22.90, M S E=0.03, p<.01$. Duncan's multiple range test showed that the differences with the unrelated control prime were all significant at the .01 level. The net phonological priming effect of $6 \%$ was significant in the analysis over participants $\left(p_{1}<.05\right)$, but not over stimulus materials $\left(p_{2}=.18\right)$.

To test the relationship of the present data with those of Brysbaert et al. (1999, Experiment 2), we performed an ANOVA on the net phonological priming effect in the three groups of participants (monolingual, Dutch-French bilingual, and French-Dutch bilingual). In this analysis, there was a reliable difference between the groups, $F_{1}(2,96)=8.43, M S E=0.03, p<.01$, and $F_{2}(2,70)=$ 7.52, $M S E=0.04, p<.01$, which was due to the difference between the monolingual group $(-9 \%)$ and the two groups of bilinguals (7\% and 6\%; critical ranges of the Newman-Keuls test at the .01 level are $F_{1}$, Step $1=.11$, Step $2=.13 ; F_{2}$, Step $1=$ .12 , Step $2=.14$ ).

Correlation between the naming latencies and the phonological priming effect. Another noteworthy outcome of Experiment 2 is that the similarity of the phonological priming effects for the French-Dutch and the Dutch-French bilinguals was not in line with the difference in naming latencies between L1 and L2 (Figure 1). To further examine the relationship between naming and phonological priming, we plotted the difference in naming latencies between L2 and L1 against the net cross-lingual phonological priming effect. (This could be done for only the French-Dutch bilinguals, as the Dutch-French bilinguals of Experiment 1 were not the same as those of Brysbaert et al., 1999, Experiment 2.) Figure 2 shows the outcome. Although there was a trend toward a negative correlation, it did not attain significance $(r=-.17, n=$ $38, p>.10$ ). Therefore, the difference between L1 and L2 naming, which proved a powerful marker to distinguish French-Dutch from Dutch-French bilinguals, has but a loose relationship with phonological mediation in visual word recognition. ${ }^{2}$

\section{Discussion}

Although the reliability of the phonological effects ideally could have been a bit more robust, the picture emerging from Experiment 2 is that of the French-Dutch bilinguals behaving much more like the Dutch-French bilinguals of Brysbaert et al. (1999) than like the French monolinguals. If we first look at the French-French stimuli, we see that although the difference failed to reach significance, both groups of bilinguals tended to show a reduced phonological priming effect relative to the French monolinguals. Whereas this effect in the Brysbaert et al. study could have been interpreted as evidence for phonological coding being less important in L2 than in L1 (see the dual-route interpretation discussed above), the present findings strongly argue against such an interpretation. In our study, French was the native language of the participants, as can be checked from the naming data in Figure 1.

So, what we find here is that French-Dutch bilinguals tend to show a smaller phonological priming effect in their native language than do French monolinguals. This finding is more in line with the second explanation suggested by Brysbaert et al. (1999) for the difference between bilinguals and monolinguals. This interpretation suggests that the reduced phonological priming effect occurs because the phonological difference between the primes fain and faic is larger for French monolinguals than it is for French-Dutch bilinguals. The reason for this difference is that in French, but not in Dutch, the end consonant changes the pronunciation of the vowels (e.g., in French, the letters ai in fain are pronounced like the letter $i$ in timbre, whereas the pronunciation of $a i$ in faic is similar to that of the letters ea in steak; in Dutch, on the other hand, the letters ai are always pronounced like the English word eye). Therefore, if in visual word recognition the letter-sound correspondences of all known languages are activated and used, then the phonological similarity between fain and faic will be larger for someone who knows Dutch than for someone who knows only French. Further evidence for this interpretation can be found in the observation that the reduced phonological priming effect in the bilingual groups was not due to worse performance in the homophonic (fain-FAIM) trials but rather to better performance in the graphemic control (faic-FAIM) trials (see Table 1).

For the Dutch-French stimuli, the pattern of results is again a replica of the data observed in Dutch-French bilinguals and deviates from the pattern displayed by French monolinguals. Whereas the latter showed worse target word recognition after a homophonic prime than after a graphemic control prime, both groups of bilinguals showed better performance. Also, the magnitude of the effect was the same. This is in line with strong phonological models of visual word recognition, which claim that in the first processing stages of visual word recognition, the letters are converted into sounds, which are needed to address the stored lexical representations. Because the recoding is thought to happen automatically and in parallel for all known letter-sound mappings, factors such as the frequency of the target words or the language dominance of the participants are not expected to make a real difference.

Finally, our data indicate that word naming latencies are not a good measure of the degree of nonlexical phonological coding in L1 and L2. For the French-Dutch bilinguals, the difference in naming latency between L2 and L1 did not correlate with the cross-lingual phonological priming effect. Furthermore, the crosslingual phonological priming effect was the same for FrenchDutch as for Dutch-French bilinguals, despite the considerable difference in naming speed as a function of the language. These

\footnotetext{
${ }^{2}$ The correlation tended to be slightly more pronounced for the highfrequency words than for the low-frequency words (LLFR: $r=.01$; LFR: $r=-.12$; HFR: $r=-.08$; HHFR: $r=-.26$ ), but it did not attain significance.
} 


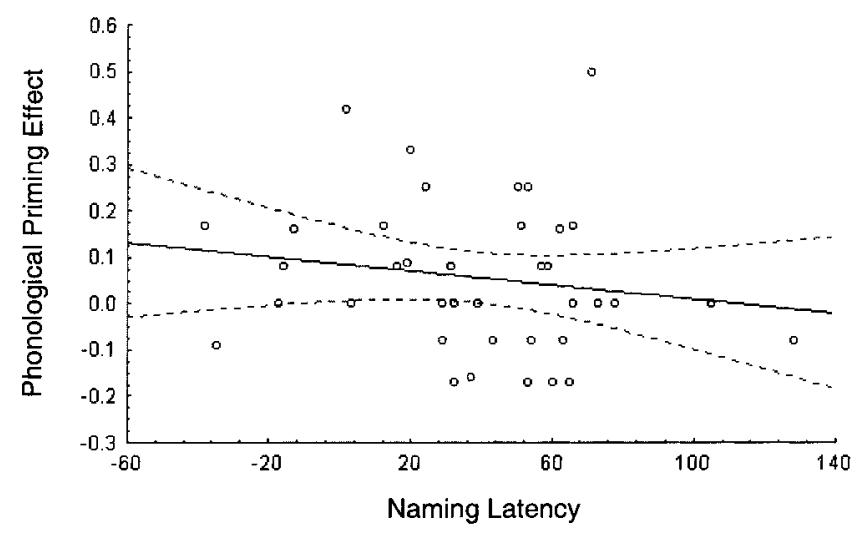

Figure 2. Correlation between the difference in naming latency between Dutch and French (Figure 1) and the net cross-lingual phonological priming effect (Table 2) for the French-Dutch bilinguals. Priming $=.08605-$ $.0008 \times$ Naming; $r=-.1651$.

findings add to the growing body of literature showing that phonological mediation in visual word recognition is based on other, probably less-detailed, representations than the correct pronunciation of words (e.g., Berent \& Perfetti, 1995; Frost, 1998). For instance, it has been shown that acquired dyslexic people who can no longer determine explicitly whether the word pairs bribe-tribe and couch-touch rhyme still show the same implicit phonological effect as people without dyslexia in a lexical decision task (Are both stimuli words or not?). That is, their response latencies were faster on the bribe-tribe trials than on the couch-touch trials (Buchanan, Hildebrandt, \& MacKinnon, 1996; Katz \& Lanzoni, 1992). Similarly, Berent (1997), using a lexical decision task with masked priming, reported a phonological priming effect in the absence of a regularity effect. There was no difference in RT between words with a regular pronunciation and words with an irregular pronunciation. Still, RTs were faster after a homophonic prime than after a graphemic control prime.

\section{General Discussion}

One of the main issues in the current literature of visual word recognition is the question concerning to what extent visual word recognition depends on phonological information. The growing consensus is that traces of a phonological contribution are always present when the experimental task taps in the very first, prelexical, stages of visual word recognition. The prototype of this type of task is the masked priming paradigm. Using that paradigm, researchers have reported a net phonological priming effect under a variety of circumstances that would reduce the reliance on phonological information if the system had any strategic control on the use of this information (Berent, 1997; Brysbaert, 2001; Xu \& Perfetti, 1999).

Brysbaert et al. (1999) reasoned that a strong phonological model of visual word recognition also has implications for bilingual language processing. If phonology is recovered in a mandatory way from the visual input and if its use cannot be strategically controlled, then all grapheme-phoneme correspondences mastered by an individual must be activated, just as the English nonword heaf activates the phonological rhymes associated with leaf and deaf (Glushko, 1979; Kay \& Marcel, 1981). Thus, it must be possible to observe cross-language phonological priming with the masked priming paradigm. This is exactly what Brysbaert et al. found: Target words in the second language were more likely to be recognized, not only when they were primed with a pseudohomophone of the same language, but also when they were primed with a pseudohomophone of the first language, even though participants were not told about the presence of such stimuli.

On the basis of this finding, Brysbaert et al. (1999; see also Brysbaert, 1998) claimed that words of the different languages mastered by a multilingual in the first stages of visual word processing behave very much like words of the same language. However, this claim was not completely supported by the data. Brysbaert et al. (1999) showed only that the letter-sound correspondences of the native language are not suppressed when words of the second language are read. As reported above, it might be argued that this finding can be accounted for by a dual-route model under the assumption that the nonlexical grapheme-to-phoneme system is limited to the GPC rules of the native language. Such a model would predict (a) the presence of a strong word frequency effect in the naming of L2 words, (b) a reduced frequency effect in the naming of L1 words, and (c) an influence of L1 phonology on the processing of L2 words, which was exactly the pattern observed in Brysbaert et al. (1999) and in Experiment 1 of the present article. However, such a model would also predict the absence of phonological priming from L2 to L1, because a rule-based grapheme-to-phoneme conversion system does not tolerate inconsistencies in the conversions and, hence, cannot support divergent conversions in two different languages (as was the case for our cross-lingual homophonic primes, which were only pseudohomophones according the nontarget language). The findings of Experiment 2 clearly rule out this prediction: There was no difference in the net phonological priming effect from L2 to L1 than from L1 to L2.

In contrast, our findings are fully compatible with connectionist types of grapheme-to-phoneme conversions (e.g., Plaut, McClelland, Seidenberg, \& Patterson, 1996; Van Orden \& Goldinger, 1994; Van Orden, Pennington, \& Stone, 1990). These models can handle inconsistencies in the spelling-sound relationships, but predict that the time to recover the phonology from a printed word depends on (a) the frequency of the word, (b) the frequency of words with the same letter-sound mapping (so-called friends), and (c) the frequency of words with an incompatible letter-sound mapping (so-called enemies). Added to this type of conversion, Frost (1998), among others (e.g., Berent \& Perfetti, 1995; Nas, 1983), argued that the prelexical phonology need not be as complete (and correct) as the phonology required for the correct pronunciation of a word. This means that the effects of word frequency and letter-sound consistency will be more pronounced (and possibly under strategic control) in naming than in masked priming, exactly the pattern we observed in our Experiments 1 and 2. According to Frost's (1998) computational model of word naming, there is no distinction between a lexical and a nonlexical route, but phonology is always prelexically assembled and, if the task requires detailed phonology, lexically supported. In this view, the lexicon merely fills in (or corrects) the gaps left open by what has already been assembled by nonlexical computations. This lexical support may explain, for instance, why word naming in L2 depends more on word frequency than word naming in L1, when 
there is no difference in the prelexical, assembled phonology between both languages. Word naming requires lexical support because the phonology must be correct and complete, whereas the assembled phonology can be quite impoverished.

Frost's (1998) model may also help us to understand what happens on the prelexical phonological level when one learns a new language. For a start, it is rarely the case that languages that share the same alphabet have completely incompatible lettersound mappings. Usually, many letters have a similar pronunciation (e.g., the $b$ is pronounced similarly in French and in Dutch). Other letter combinations only exist in one of the two languages, and also do not cause difficulties for the spelling-sound conversion system (because there is no inconsistency). This means that from the beginning of the language acquisition process, a great deal of the phonology of the new language is available to the lexicon. Gradually, the inconsistencies in the letter-sound mappings between both languages are incorporated in the network (in the same way that inconsistencies within a language become incorporated), until in the end, the letter-sound mappings of the new language are not only mastered but also start to have an influence on the letter-sound conversions of the native language. ${ }^{3}$ As can be seen in Table 1, the bilinguals not only differed from the monolinguals on the cross-lingual, Dutch-French stimuli, but also tended to differ on the intralingual French-French stimuli, in which the phonological priming effect was slightly smaller for bilinguals than for monolinguals, probably because of the larger phonological similarity between the homophonic and the graphemic control primes in the nontarget language than in the target language.

The finding that phonological priming is possible from L2 to L1 has implications not only for theories of phonological mediation in visual word recognition, but also for theories of bilingual language processing. In particular, this finding is further evidence that visual word recognition in multilinguals is less language specific than has been assumed until recently. Even though the participants believed they were tested about their mother tongue, they could not prevent themselves from being influenced by their (much more limited) knowledge of a second language. As such, the present findings add to the growing body of evidence that language-selective access to the mental lexicon does not exist.

\footnotetext{
${ }^{3}$ An interesting way to get more insight into the nature of the prelexical phonological code may indeed be to examine in close detail what happens when the relative frequencies of the grapheme-phoneme correspondences in L1 and L2 are manipulated. On the basis of research with English monolinguals (e.g., Lukatela, Frost, \& Turvey, 1999), one can predict that the cross-lingual phonological priming effect will be larger for primes in which the critical graphemes have a higher frequency of occurrence and a more consistent pronunciation in the language of the prime than in the language of the target, relative to primes in which the critical graphemes have a lower frequency and/or a less consistent pronunciation in the language of the prime than in the language of the target (cf. the balance of friends and enemies in the connectionist networks). Contrary to the rulebased models, parallel distributed processing networks predict a gradual effect of these stimulus characteristics (also depending on the importance of the critical graphemes for establishing the prelexical phonological code) rather than all-or-none effects that are based on whether the required grapheme-to-phoneme conversion is part of the rule set. We thank an anonymous reviewer for pointing us to this prediction.
}

\section{References}

Baayen, R. H., Piepenbrock, R., \& Van Rijn, H. (1993). The CELEX Lexical Database [Computer software]. Philadelphia, PA: University of Pennsylvania, Linguistic Data Consortium.

Berent, I. (1997). Phonological priming in the lexical decision task: Regularity effects are not necessary evidence for assembly. Journal of Experimental Psychology: Human Perception and Performance, 23, 1727-1742.

Berent, I., \& Perfetti, C. A. (1995). A rose is a REEZ: The two-cycles model of phonology assembly in reading English. Psychological Review, 102, 146-184.

Bijeljac-Babic, R., Biardeau, A., \& Grainger, J. (1997). Masked orthographic priming in bilingual word recognition. Memory \& Cognition, 25, 447-457.

Bovens, N., \& Brysbaert, M. (1990). IBM PC/XT/AT and PS/2 Turbo Pascal timing with extended resolution. Behavior Research Methods, Instruments \& Computers, 22, 332-334.

Brysbaert, M. (1994). Interhemispheric transfer and the processing of foveally presented stimuli. Behaviour Brain Research, 64, 151-161.

Brysbaert, M. (1998). Word recognition in bilinguals: Evidence against the existence of two separate lexicons. Psychologica Belgica, 38, 163-175.

Brysbaert, M. (2001). Prelexical phonological coding of visual words in Dutch: Automatic after all. Memory \& Cognition, 29, 765-773.

Brysbaert, M., Lange, M., \& Van Wijnendaele, I. (2000). Age-ofacquisition of words is a significant variable in semantic tasks. European Journal of Cognitive Psychology, 12, 65-85.

Brysbaert, M., Van Dyck, G., \& Van de Poel, M. (1999). Visual word recognition in bilinguals: Evidence from masked phonological priming. Journal of Experimental Psychology: Human Perception and Performance, 25, 137-148.

Brysbaert, M., Vitu, F., \& Schroyens, W. (1996). The right visual field advantage and the optimal viewing position effect: On the relation between foveal and parafoveal word recognition. Neuropsychology, 10, 385-395.

Buchanan, L., Hildebrandt, N., \& MacKinnon, G. E. (1996). Phonological processing of nonwords in deep dyslexia: Typical and independent? Journal of Neurolinguistics, 9, 113-133.

Centre National de la Recherche Scientifique. (1971). Trésor de la langue Française. Nancy, France: Author.

Coltheart, M. (1978). Lexical access in simple reading tasks. In G. Underwood (Ed.), Strategies of information processing (pp. 151-216). London: Academic Press.

Coltheart, M., Curtis, B., Atkins, P., \& Haller, M. (1993). Models of reading aloud: Dual-route and parallel-distributed-processing approaches. Psychological Review, 100, 589-608.

Coltheart, M., Rastle, K., Perry, C., Langdon, R., \& Ziegler, J. C. (2001). DRC: A dual route cascaded model of visual word recognition and reading aloud. Psychological Review, 108, 204-256.

De Groot, A. M. B., Delmaar, P., \& Lupker, S. J. (2000). The processing of interlexical homographs in translation recognition and lexical decision: Support for non-selective access to bilingual memory. Quarterly Journal of Experimental Psychology: Human Experimental Psychology, 53(A), 397-428.

Dijkstra, A., Grainger, J., \& van Heuven, W. J. B. (1999). Recognition of cognates and interlingual homographs: The neglected role of phonology. Journal of Memory and Language, 41, 496-518.

Dijkstra, A., Timmermans, M., \& Schriefers, H. (2000). On being blinded by your other language: Effects of task demands on interlingual homograph recognition. Journal of Memory and Language, 42, 445-464.

Dijkstra, A., \& van Heuven, W. J. B. (1998). The BIA model and bilingual word recognition. In J. Grainger \& A. M. Jacobs (Eds.), Localist connectionist approaches to human cognition (pp. 189-225). Mahwah, NJ: Erlbaum.

Dijkstra, A., Van Jaarsveld, H., \& Ten Brinke, S. (1998). Interlingual 
homograph recognition: Effects of task demands and language intermixing. Bilingualism: Language and Cognition, 1, 51-66.

Ferrand, L., \& Grainger, J. (1993). The time course of orthographic and phonological code activation in the early phases of visual word recognition. Bulletin of the Psychonomic Society, 31, 119-122.

Ferrand, L., \& Grainger, J. (1994). Effects of orthography are independent of phonology in masked form priming. Quarterly Journal of Experimental Psychology: Human Experimental Psychology, 47(A), 365-382.

Frost, R. (1998). Toward a strong phonological theory of visual word recognition: True issues and false trails. Psychological Bulletin, 123, 71-99.

Frost, R., Katz, L., \& Bentin, S. (1987). Strategies for visual word recognition and orthographical depth: A multilingual comparison. Journal of Experimental Psychology: Human Perception and Performance, 13, 104-115.

Glushko, R. J. (1979). The organization and activation of orthographic knowledge in reading aloud. Journal of Experimental Psychology: Human Perception and Performance, 5, 674-691.

Grainger, J., \& Ferrand, L. (1996). Masked orthographic and phonological priming in visual word recognition and naming: Cross-tasks comparisons. Journal of Memory and Language, 35, 623-647.

Grosjean, F. (1997). Processing mixed languages: Issues, findings and models. In A. de Groot \& J. Kroll (Eds.), Tutorials in bilingualism: Psycholinguistic perspectives (pp. 225-254). Hillsdale, NJ: Erlbaum.

Grosjean, F. (1998). Studying bilinguals: Methodological and conceptual issues. Bilingualism: Language and Cognition, 1, 131-149.

Humphreys, G. W., Evett, L. J., \& Taylor, D. E. (1982). Automatic phonological priming in visual word recognition and naming: Cross task comparisons. Memory \& Cognition, 10, 576-590.

Katz, R. B., \& Lanzoni, S. M. (1992). Automatic activation of word phonology from print in deep dyslexia. Quarterly Journal of Experimental Psychology: Human Experimental Psychology, 45(A), 575-608.

Kay, J., \& Marcel, A. (1981). One process, not two, in reading aloud: Lexical analogies do the work of non-lexical rules. Quarterly Journal of Experimental Psychology: Human Experimental Psychology, 33(A), 397-413.

Kroll, J. F., \& Stewart, E. (1994). Category interference in translation and picture naming: Evidence for asymmetric connections between bilingual memory representations. Journal of Memory and Language, 33, 149174.

La Heij, W., Hooglander, A., Kerling, R., \& van der Velden, E. (1996). Nonverbal context effects in forward and backward word translation: Evidence for concept mediation. Journal of Memory and Language, 35, $648-665$.
Lukatela, G., Frost, S. J., \& Turvey, M. T. (1999). Identity priming in English is compromised by phonological ambiguity. Journal of Experimental Psychology: Human Perception and Performance, 25, 775-790.

McClelland, J. L., \& Rumelhart, D. E. (1981). An interactive-activation model of context effects in better perception: Part 1 . An account of basic findings. Psychological Review, 88, 375-405.

Nas, G. (1983). Visual word recognition in bilinguals: Evidence from cooperation between visual and sound based codes during access to common lexical store. Journal of Verbal Learning and Verbal Behavior, 23, 526-534.

Peereman, R., \& Content, A. (1995). Neighborhood size effect in naming: Lexical activation or sublexical correspondences? Journal of Experimental Psychology: Learning, Memory, and Cognition, 21, 409-421.

Perfetti, C. A., \& Bell, L. C. (1991). Phonemic activation during the first $40 \mathrm{~ms}$ of word identification: Evidence from backward masking and priming. Journal of Memory and Language, 27, 59-70.

Plaut, D. C., McClelland, J. L., Seidenberg, M. S., \& Patterson, K. (1996). Understanding normal and impaired word reading: Computational principles in quasi-regular domains. Psychological Review, 103, 56-115.

Schaerlaekens, A. (1998). Bilingualism in children: An introduction. Psychologica Belgica, 38, 129-148.

Segui, J., \& Grainger, J. (1990). Priming word recognition with orthographic neighbors: Effects of relative prime-target frequency. Journal of Experimental Psychology: Human Perception and Performance, 16, $65-75$.

Van den Bosch, A., Content, A., Daelemans, W., \& De Gelder, B. (1994). Measuring the complexity of writing systems. Journal of Quantitative Linguistics, 1, 178-188.

Van Heuven, J. B., Dijkstra, T., \& Grainger, J. (1998). Orthographic neighborhood effects in bilingual word recognition. Journal of Memory and Language, 39, 458-483.

Van Orden, G. C. (1987). A ROWS is a ROSE: Spelling, sound, and reading. Memory \& Cognition, 15, 181-198.

Van Orden, G. C., \& Goldinger, S. D. (1994). Interdependence of form and function in cognitive systems explains perception of printed words. Journal of Experimental Psychology: Human Perception and Performance, 20, 1269-1291.

Van Orden, G. C., Pennington, B. F., \& Stone, G. O. (1990). Word identification in reading and the promise of subsymbolic psycholinguistics. Psychological Review, 97, 488-522.

Xu, B., \& Perfetti, C. A. (1999). Nonstrategic subjective threshold effects in phonemic masking. Memory \& Cognition, 27, 26-36. 


\section{Appendix A}

French and Dutch Stimuli for Experiment 1

Table A1

Very Low Frequency (1-10 Occurrences per Million Words)

\begin{tabular}{|c|c|c|c|c|c|c|c|}
\hline \multicolumn{4}{|c|}{ Dutch } & \multicolumn{4}{|c|}{ French } \\
\hline 3 & 4 & 5 & 6 & 3 & 4 & 5 & 6 \\
\hline sla & vete & aapje & oorlel & mec & écru & mimer & jasmin \\
\hline mep & voeg & erker & vergif & bru & flou & cible & garnir \\
\hline web & kuip & dolen & onrijp & cep & crin & tarif & quérir \\
\hline vlo & loof & ivoor & weelde & été & heur & colon & camper \\
\hline muf & belg & getij & woelen & mil & chut & béret & cordon \\
\hline kok & luis & effen & liedje & bac & cerf & décès & festin \\
\hline dij & zalm & ijdel & aldoor & $\operatorname{lin}$ & croc & jupon & menton \\
\hline zot & zuid & weide & vallei & cap & clin & photo & gibier \\
\hline uil & lade & ovaal & volume & axe & bise & gazon & épouse \\
\hline wol & koek & anker & kalmte & mât & clan & curée & lustre \\
\hline
\end{tabular}

Table A2

Low Frequency (10-100 Occurrences per Million Words)

\begin{tabular}{|c|c|c|c|c|c|c|c|}
\hline \multicolumn{4}{|c|}{ Dutch } & \multicolumn{4}{|c|}{ French } \\
\hline 3 & 4 & 5 & 6 & 3 & 4 & 5 & 6 \\
\hline kar & buur & uniek & hijgen & mûr & bain & plier & soupir \\
\hline ijs & hoed & rijke & geweer & thé & port & pomme & statue \\
\hline koe & zand & engel & eeuwig & fin & banc & tache & mouton \\
\hline zon & maan & nabij & jammer & fil & faim & repas & crever \\
\hline kat & vaag & tocht & geweld & vif & gris & reine & ménage \\
\hline eis & adem & visie & wenden & cou & posé & mêler & vendre \\
\hline bos & mede & vrije & dansen & dur & juge & oncle & membre \\
\hline pak & wang & zijde & ideaal & sec & avis & herbe & empire \\
\hline dun & rode & keuze & nummer & pli & égal & glace & marché \\
\hline tak & ring & opzij & majoor & ému & poil & mince & pudeur \\
\hline
\end{tabular}

Table A3

High Frequency (100-1,000 Occurrences per Million Words)

\begin{tabular}{|c|c|c|c|c|c|c|c|}
\hline \multicolumn{4}{|c|}{ Dutch } & \multicolumn{4}{|c|}{ French } \\
\hline 3 & 4 & 5 & 6 & 3 & 4 & 5 & 6 \\
\hline gek & mate & stoel & waarde & fer & page & fleur & revoir \\
\hline wet & koud & angst & gevoel & cri & coin & train & secret \\
\hline bed & oude & tafel & hangen & dix & bête & désir & mourir \\
\hline erg & jong & boven & praten & ici & long & reste & sortir \\
\hline elk & enig & vader & buiten & ami & côté & porte & rester \\
\hline mee & drie & eigen & anders & nom & vrai & ainsi & contre \\
\hline dus & huis & nooit & manier & cet & soir & moins & tomber \\
\hline weg & even & groep & steken & car & déjà & cause & simple \\
\hline wie & zelf & vrouw & weinig & vie & donc & heure & parler \\
\hline jij & werk & sterk & dienen & toi & sens & corps & suivre \\
\hline
\end{tabular}

Table A4

Very High Frequency (Greater Than 10,000 Occurrences per Million Words)

\begin{tabular}{|c|c|c|c|c|c|c|c|}
\hline \multicolumn{4}{|c|}{ Dutch } & \multicolumn{4}{|c|}{ French } \\
\hline 3 & 4 & 5 & 6 & 3 & 4 & 5 & 6 \\
\hline ook & deze & onder & hebben & lui & même & venir & savoir \\
\hline nog & zien & groot & worden & sur & voir & grand & encore \\
\hline uit & over & geven & kunnen & mon & avec & petit & devoir \\
\hline bij & zich & tegen & zullen & que & nous & homme & jamais \\
\hline die & maar & laten & zeggen & qui & mais & aller & \\
\hline hij & voor & weten & moeten & peu & pour & autre & \\
\hline een & doen & staan & willen & ses & bien & cette & \\
\hline het & gaan & ander & alleen & par & sans & faire & \\
\hline dan & niet & maken & denken & une & vous & avoir & \\
\hline van & zijn & komen & vinden & aux & être & comme & \\
\hline
\end{tabular}

\section{Appendix B}

French-French Stimuli of Experiment 2

\begin{tabular}{|c|c|c|c|}
\hline Target & Prime 1 & Prime 2 & Prime 3 \\
\hline FAIM & fain & fint & faic \\
\hline LENT & lens & lamp & lene \\
\hline BORD & bore & baur & borl \\
\hline PAIR & peir & pers & plir \\
\hline BEAU & bhau & baut & blau \\
\hline TORT & tors & taur & torc \\
\hline THYM & thyn & tein & thyr \\
\hline NERF & nert & nair & nerc \\
\hline TAUX & taud & tots & tauf \\
\hline BAIN & baim & bint & bait \\
\hline VENT & vens & vamd & vene \\
\hline ZINC & zint & zein & zine \\
\hline NORD & nore & naur & norc \\
\hline VERS & verd & vair & verg \\
\hline LAID & lais & lets & lain \\
\hline FORT & fore & faur & fork \\
\hline MAIN & maim & mins & maig \\
\hline MAUX & maut & meau & maul \\
\hline SAIN & saim & $\operatorname{sint}$ & saie \\
\hline FAIT & faie & fets & fail \\
\hline DENT & dens & damp & dene \\
\hline VAIN & vaim & vint & vail \\
\hline SORT & sore & saur & sora \\
\hline MERE & mert & mair & merq \\
\hline BAIE & bait & bets & bair \\
\hline ROSE & roze & rauz & rove \\
\hline SOLE & sols & saul & solt \\
\hline FILS & fiss & phys & firs \\
\hline FAUX & faud & fots & fauc \\
\hline BANC & bant & bemp & bane \\
\hline \multicolumn{4}{|c|}{$\begin{array}{l}\text { Note. Prime } 1=\text { pseudohomophonic prime with orthographic overlap } \\
\text { with the target; Prime } 2=\text { pseudohomophonic prime, but with small } \\
\text { orthographic overlap with the target; Prime } 3=\text { graphemic control prime. } \\
\text { From "Masked Orthographic and Phonological Priming in Visual Word } \\
\text { Recognition and Naming: Cross-Tasks Comparisons," by J. Grainger and } \\
\text { L. Ferrand, 1996, Journal of Memory and Language, 35, p. 643. Copyright } \\
1996 \text { by Academic Press. Reprinted with permission. }\end{array}$} \\
\hline
\end{tabular}




\section{Appendix C}

Dutch-French Stimuli of Experiment 2

\begin{tabular}{|c|c|c|c|}
\hline Target & Homophone & $\begin{array}{c}\text { Graphemic } \\
\text { control }\end{array}$ & $\begin{array}{c}\text { Unrelated } \\
\text { control }\end{array}$ \\
\hline SOURD & soer & siard & chane \\
\hline RIRE & rier & rine & bomp \\
\hline SAUCE & soos & sour & moir \\
\hline NUQUE & nuuk & nuus & vees \\
\hline FOULE & foel & fole & gart \\
\hline MOULE & moel & mols & nars \\
\hline FOUR & foer & forg & mels \\
\hline POUR & poer & poir & dalk \\
\hline AMOUR & amoer & amoir & eleen \\
\hline BILE & biel & bilg & muns \\
\hline PILE & piel & pilm & ruum \\
\hline AVARE & avaar & avauw & omont \\
\hline SAC & sak & saf & dif \\
\hline FACE & fas & fane & gol \\
\hline TRACE & tras & trare & snuc \\
\hline PUCE & puus & puir & reir \\
\hline CUITE & kwiet & brite & broms \\
\hline DROLE & drool & droul & stane \\
\hline VITE & viet & vits & hols \\
\hline PLUME & pluum & plums & graap \\
\hline CRIME & kriem & treim & plous \\
\hline CAVE & kaaf & zaar & zoor \\
\hline TOUTE & toet & taute & lifs \\
\hline FOU & foe & for & har \\
\hline TROU & troe & tron & pnal \\
\hline VOUS & voe & vost & zart \\
\hline CLOU & kloe & blon & bren \\
\hline COUPE & koep & roop & dijf \\
\hline DOUCE & does & doire & zair \\
\hline LUNE & luun & luin & gair \\
\hline FAUTE & foot & feute & zors \\
\hline HUIT & wiet & gait & koem \\
\hline SITE & siet & sive & cord \\
\hline SOURCE & soers & soork & weelk \\
\hline ROLE & rool & roge & gauf \\
\hline CORPS & kor & nort & nult \\
\hline
\end{tabular}

Note. From "Visual Word Recognition in Bilinguals: Evidence From Masked Phonological Priming," by M. Brysbaert, G. Van Dyck, and M. Van de Poel, 1999, Journal of Experimental Psychology: Human Perception and Performance, 25, p. 148. Copyright 1999 by the American Psychological Association.

Received November 22, 1999

Revision received July 11, 2001

Accepted September 7, 2001 